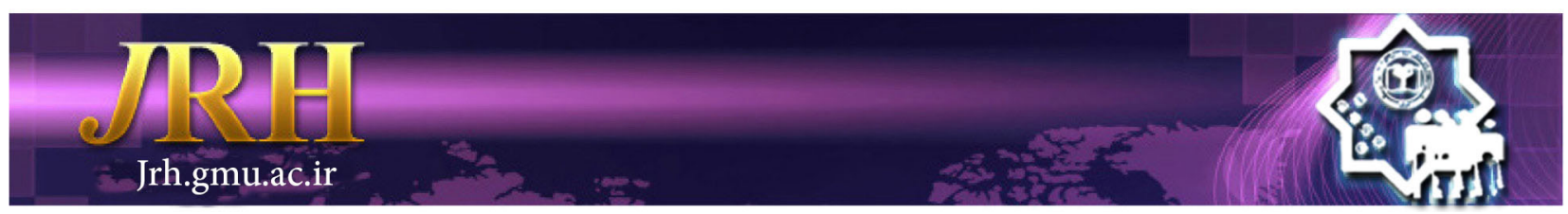

\title{
The effect of health-related messages on the behavior of social network audiences according to attention, interest, desire, action model
}

\author{
Abolfazl Danaei ${ }^{1}$, Neda Sadat Sanei ${ }^{1}$
}

\author{
Journal of Research \& Health \\ Social Development \& Health Promotion \\ Research Center \\ Vol. 9, No. 6, Nov \& Dec 2019 \\ Pages: $525-532$ \\ DOI: 10.32598 /jrh.9.6.525 \\ Original Article
}

1. Department of Management, Semnan Branch, Islamic Azad University, Semnan, Iran

Correspondence to: Abolfazl Danaei, Department of Media Management, Semnan Branch, Islamic Azad University, Semnan, Iran

Email: a.danaei@semnaniau.ac.ir

Received: 24 Sep 2017

Accepted: 1 Jan 2018

How to cite this article: Danaei A, Sanei NS. The effect of health-related messages on the behavior of social network audiences according to Attention, Interest, Desire, Action model. J Research \& Health2019; 9(6): 525532 .

\begin{abstract}
Nowadays the audience's behaviors and reactions to health-related messages are of great importance. The present research aimed at studying the effect of health-related messages on the behaviors of social networks audiences according to attention, interest, desire, action model. The study used structural equation modeling to analyze the gathered data. The data were collected from the audiences of Telegram social network in Iran by using a questionnaire whose reliability and validity had been confirmed. The participants were selected by adopting a simple random sampling approach. The data of 384 questionnaires were analyzed. The findings of the present study indicated that health-related messages have positive significant effects on the behaviors of social networks audiences. Moreover, the findings of the present study confirmed the effects of physical, social, spiritual, and mental health on attracting attention, building interest, arousing desire, and persuading to take action among social networks audiences. Therefore, according to the research findings, it can be said that health-related messages sent to the audiences of Telegram social network can change the behavior of audiences. In other words, it can be concluded that health-related messages can affect the behaviors of social networks audiences.
\end{abstract}

Keywords: Behavior, Health, Message, Social Networking

\section{Introduction}

Given the intense competition existing among the companies as well as the quick changes in the users' behaviors in a consumer society, advertising messages are regarded as an important tool for raising awareness among the consumers [1]. Thus, for the advertising messages to be more effective in the consumers' behaviors, one needs to select appropriate behavioral models by conducting more studies, so that the companies achieve their goals in this respect [2]. One of the most effective behavioral models is the
Attention, Interest, Desire, Action (AIDA) model that has a significant importance. By having four components including attracting attention, building interest, arousing desire, and persuading to take action or leading them towards purchasing or taking a specific action, this model has a lot of advocates. The present study applies the AIDA model [3]. The significance of applying this model in the present study is the appropriateness of the model with the intended research and field of action 
for its comprehensive components as well as the popularity of this model in behavioral studies conducted so far. Moreover, health originates from the social, cultural, economic, and even political factors and conditions of society and it is a reflection of the individuals' conditions in every society. In the modern world, given the technological achievements and their direct effect on the quality of individuals' lives, the issue of health with all of its aspects including physical, social, spiritual, and mental health is of great importance; the common development goal of a given society in both national and international levels is to improve the quality of life and health [4]. In the present study, health-related messages refer to those messages dealing, either directly or indirectly, with physical, social, spiritual, and mental health. Nowadays, health policymakers have found media as an appropriate tool for disseminating health messages. Thus, it seems necessary to measure the efficacy of healthrelated messages and receive appropriate feedback from the audiences [5]. Since social networks are considered as the main source of disseminating health information and as they are extensively present in the individuals' lives, social networks have sustainable effects on the public health [6]. From among the various social networks applied in Iran, we can refer to Telegram as the most frequently used social network. Given the increasing capabilities of this network and the ease of access to messages and channels, Telegram has become even more popular, efficient, and effective. Based on the abovementioned materials, the present research aimed at studying the effect of health-related messages on the behaviors of social networks audiences according to AIDA model. Since the people in our country use this social network very often, one can say that the messages disseminated through this social network are of great importance. The first function of advertising messages is attracting the individuals' attention. If an advertising message fails to attract attention, it will not be seen nor heard by people [1]. The message sender must be able to establish a relationship with the customer. In order to advertise the message, he/ she must be aware of how customers of the target market think. Thus, the messages need to persuade the consumer that the advertised message can meet his/her needs. In building interest and arousing the individual, promotion is of great importance [7].

One of the most difficult tasks of advertising messages is arousing an individual to have or use the intended service. For arousing the customers toward the intended products or services, there are various stimuli. Depending on the kind of product or service and the customers, these stimuli need to be identified and programmed [8]. Directing the individual toward buying a specific product or task is the last function of an advertising message that is not an easy task. In directing an individual towards buying a specific product or service, the act of buying is not merely intended, and it is attempted to highlight the positive effect of buying a specific product or service [9]. By applying a content analysis method, Khashei and Zokaei [6] analyzed the healthrelated messages of four media (Health Radio, Television (TV), Salamat news website, and Salamat weekly) based on four aspects of health (physical, social, mental, and spiritual). The findings obtained indicated that in all of the four media, physical health was the most frequently discussed aspect followed by social, mental, and spiritual aspects. The physical, social, mental, and spiritual aspects were devoted the most frequency and duration, in sequence [6]. Another media mobilization of information was conducted in 2003 by Bir that lasted for two years. An extensive information-sharing program was conducted at the university campus for freshmen by applying key messages for reducing alcohol driving [10]. Yingjie was proposed in this paper for identifying automatically topics of the health-related messages in the online health community, thus assisting patients in reaching the most relevant messages for their queries efficiently. Finally, three different text classification techniques, Naïve Bayes, and Support Vector Machine (SVM), were adopted to evaluate our topic classification model. 
The experimental results demonstrated that the proposed approach could identify the topics of online health-related messages efficiently [11]. Fish and colleagues investigated recent evidence (post-2009) regarding the effectiveness of public health messaging during smoke events. Principal results were: 1) Smoke-related public health messages are communicated via a variety of channels, but limited evidence is available regarding their effectiveness for the general public or at-risk groups. 2) Messages that use simple language are more commonly recalled, understood, and complied with. Compliance differs according to socio-demographic characteristics [12]. The findings of the abovementioned study indicated that risky driving significantly reduced after conducting this research. Thus, according to what stated, the conceptual model of the present study is as shown in Figure 1.

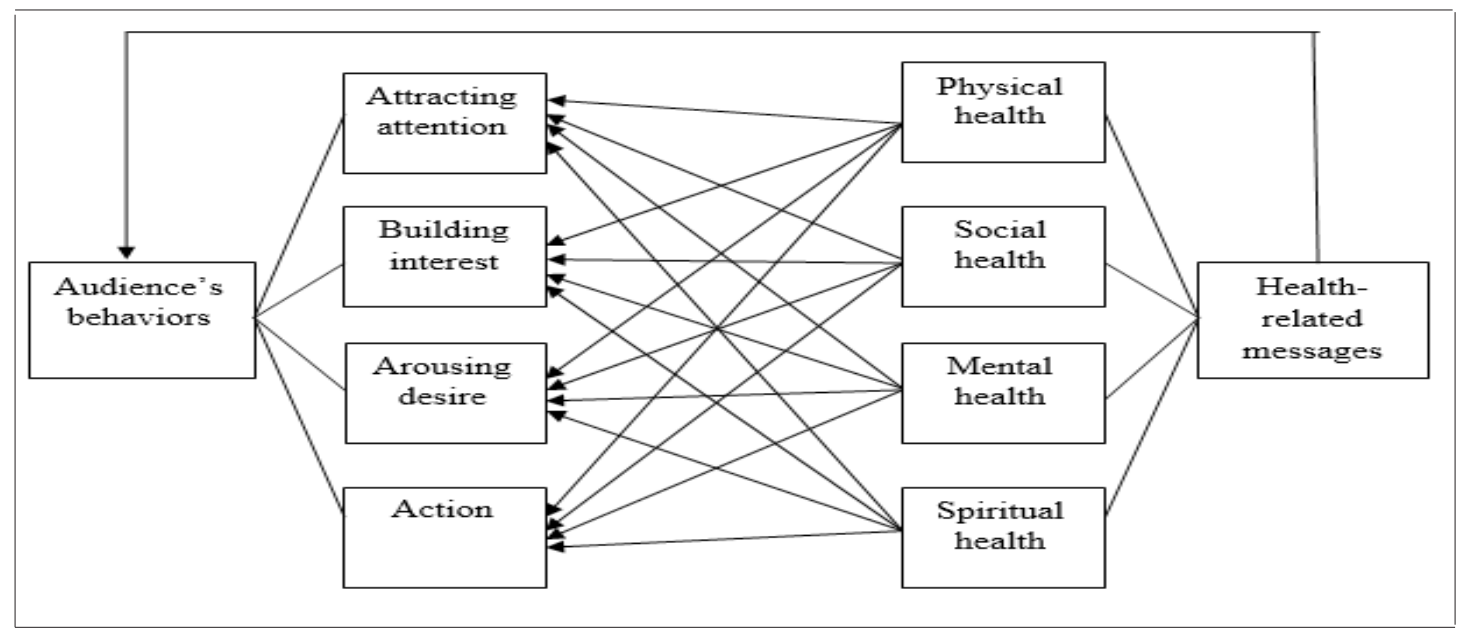

Figure 1 The conceptual model of the research

\section{Method}

This study was an applied research in terms of purpose and analytical in terms of collecting data. For measuring the social health variable, the recommended measures of Keyes study [13] were used. For physical and mental health, the items of a study conducted by Goldberg and Hiller [14] were used and for spiritual health, the items of Paloutzian \& Ellison [15] were used. A questionnaire with 34 items was designed including eight variables: physical health, mental health, spiritual health, social health, attracting attention, building interest, arousing desire, and action. The face validity of the questionnaire was confirmed by analyzing the views of management experts. Moreover, the validity of the constructs and their aspects was evaluated by using confirmatory factor analysis and the significance of each of the aspects and items was confirmed. For confirming the validity of the tool, both construct validity and convergent validity were used. For convergent validity, Average
Variance Extracted (AVE) scale was used. The value of this coefficient varies from 0 to 1 ; values higher than 0.5 are acceptable since these values secure that at least 50 percent of a construct variance is defined by its indicators [16]. Given the findings of convergent validity including the convergent validity of physical health message (0.611), social health message $(0.515)$, mental health message (0.515), spiritual health message (0.545), attention attraction of the audience (0.531), building interest among the audience (0.508), arousing desire among the audience (0.503), and the audience's action (0.627), one can conclude that the convergent validity of the model is desirable. The statistical population of the present study included the audiences of Telegram social network in Iran in August 2017 selected by simple random sampling. Thus, the sample size of the present study was 384 participants according to Cochran's formula with the unlimited 
statistical population. Cochran's formula of the study is shown in Figure 2 in which, $z=1.96$, $\mathrm{p}=\mathrm{q}=0.5$, and $(\mathrm{d}=0.05)$ that is the value of the allowable error (error value). At the end, 384 qualified questionnaires were used for analysis. The present study included 17 hypotheses analyzed by Smart Partial Least Squares (PLS) software. The data were analyzed in two levels: descriptive and inferential. For describing the aforementioned data, the indices of frequency, frequency percentage, and diagrams were obtained by using SPSS-18. Moreover, at the inferential level, structural equation modeling was used after studying the validity of the questionnaire. In addition, one limitation in this study was the data gathering from the audiences of Telegram social network that was very time consuming for the researcher due to indirect discretion to the audience and the large sample size.

\section{Results}

Characteristics of audiences of Telegram social network in the present research were studied by analyzing five demographic variables including age, gender, marital status, educational level, and average. Their results are shown in Table 1.

\begin{tabular}{lccc}
\multicolumn{4}{l}{ Table 1 Characteristics of the audiences of Telegram social network } \\
\hline \multirow{2}{*}{ Demographic variables } & State & Frequency & Frequency (\%) \\
\hline \multirow{2}{*}{ Gender } & Woman & 186 & 48.4 \\
& Man & 198 & 51.6 \\
\hline \multirow{4}{*}{ Age } & $<25$ & 101 & 26.3 \\
& $25-35$ & 167 & 43.5 \\
& $36-45$ & 82 & 21.4 \\
& $46-55$ & 30 & 7.8 \\
\multirow{4}{*}{ Education } & $>55$ & 4 & 1 \\
& Diploma & 34 & 8.9 \\
& Associate's degree & 84 & 21.9 \\
\multirow{2}{*}{ Marriage situation } & Bachelor of Science & 172 & 44.8 \\
& Master of Science & 78 & 20.2 \\
& Doctor of Philosophy & 16 & 4.2 \\
\hline
\end{tabular}

The reliability of the tool was evaluated by using Cronbach's alpha coefficient. Given that this coefficient was higher than 0.7 for most of the variables of the present study, one can say that the questionnaire is reliable enough. Exploratory Factor Analysis (EFA): In order to perform exploratory factor analysis, KaiserMeyer-Olkin test (KMO) was used to verify sample size sufficiency and Bartlett test of Sphericity to verify data suitability. As a rule, the KMO value for performing factor analysis on the data should be higher than 0.6 and the higher values of the coefficient of confidence favor the use of factor analysis. The Bartlett test of Sphericity should be meaningful, in other words, the significance level should be less than 0.05. This value was 0.01 for Bartlett test in this study. The results show that at a significant level of KMO is 0.748 , which is higher than 0.6 , so the accuracy of the data was confirmed.

Confirmatory Factor Analysis (CFA): Moreover, confirmatory factor analysis was applied to measure the validity of the tool applied in the present study. In the confirmatory factor analysis, factor loading less than 0.4 must be deleted from the model [17]. Moreover, if $t$ values are larger than 1.96 or less than -1.96 , at a $95 \%$ confidence interval, the indicators provide an appropriate factor construct for measuring different aspects of the study in the research model.

According to the results of the confirmatory factor analysis, $t$-statistic for all items was bigger than 1.96. Besides, the factor loading was bigger than 0.4 . Thus, it can be concluded that the questionnaire is valid. To test the hypotheses, the research model (Figures 1) was examined and presented in Figure 2. 


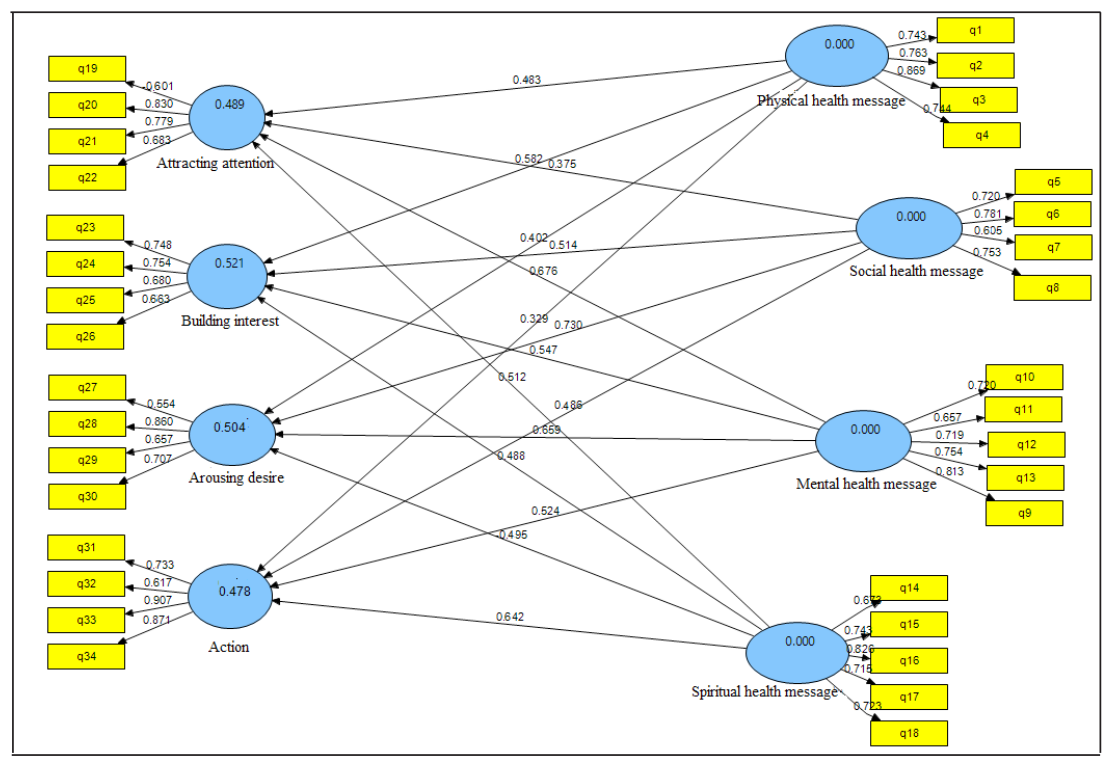

Figure 2 Factor coefficients and path coefficient of the research model

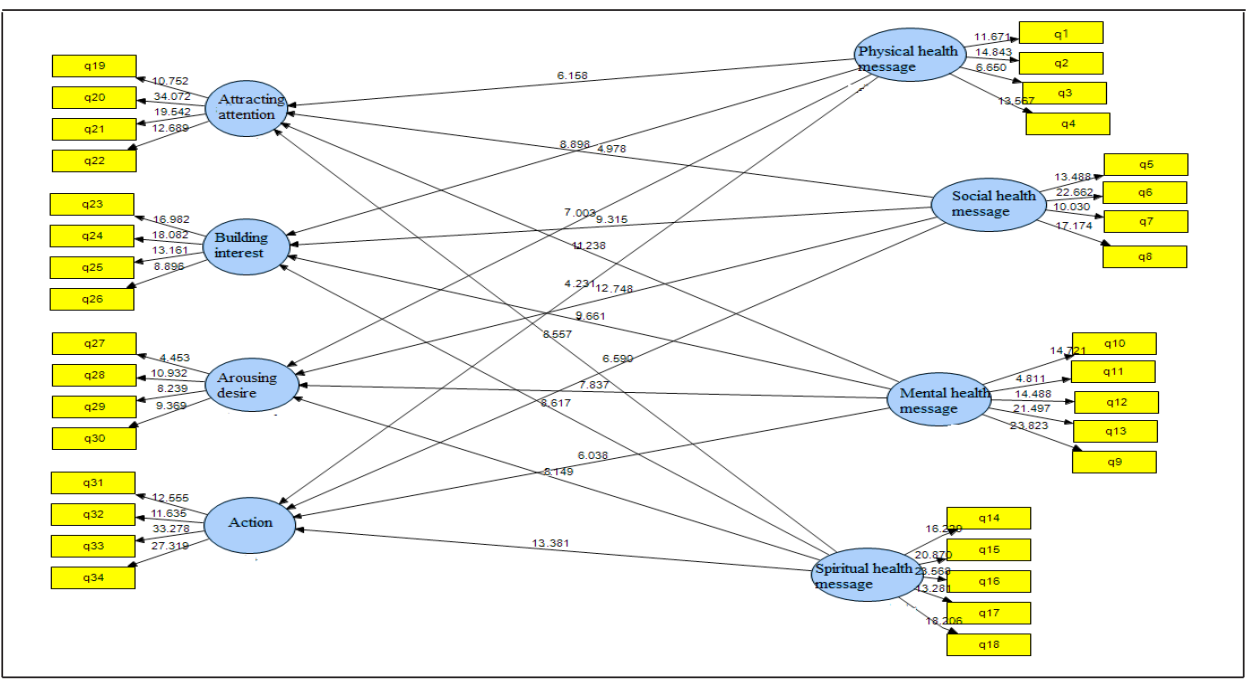

Figure 3 The findings of T-test of the research model

Moreover, given the goodness of fit indices including absolute index (0.521), relative index (0.847), external model index (0.913), and internal model index (0.928), one can say that the primary model of the research is appropriate because if the index is greater than or equal to 0.5 , the model is appropriate [16]. Given the confirmation of "goodness of fit" of the model, the next section deals with testing and analyzing the related hypotheses by using the confirmed aspects provided in Table 2 .

The second model's coefficient of determination for the audience's behavior variable was measured to be 0.545 . Moreover, goodness of fit index was measured to be 0.562 for the absolute index, 0.829 for the relative index, 0.907 for the external model index, and 0.914 for the internal model index; this indicates that the second model is appropriate because if the index is greater than or equal to 0.5 , the model is appropriate [16]. Moreover, given the confirmation of goodness of fit of the model in this section and according to the findings obtained from the structural equations, the path coefficient of health-related messages and behaviors of Telegram audiences was equal to 0.738 , which is a positive value. The t-statistic value was equal to 28.989 (Figure 3) that is larger than 1.96. Therefore, with a $95 \%$ confidence, one can claim that the health-related messages have created positive and significant effects, and thus the main hypothesis of the study is accepted. 
Health message on behavior of social network audience

Table 2 The test findings of the research hypotheses

\begin{tabular}{|c|c|c|c|}
\hline Hypotheses & $\begin{array}{c}\text { Path } \\
\text { coefficient }\end{array}$ & statistic & Result \\
\hline Physical health message $\longrightarrow$ Audience's attracting attention & 0.483 & 6.158 & Confirmed \\
\hline Physical health message $\longrightarrow$ Building interest among the audience & 0.582 & 8.898 & Confirmed \\
\hline Arousing desire among the audience & 0.402 & 7.003 & Confirmed \\
\hline Physical health message $\longrightarrow$ Audience's action & 0.329 & 4.231 & Confirmed \\
\hline Audience's attracting attention & 0.375 & 4.978 & Confirmed \\
\hline Building interest among the audience & 0.514 & 9.315 & Confirmed \\
\hline Arousing desire among the audience & 0.730 & 12.748 & Confirmed \\
\hline Social health message & 0.486 & 6. 590 & Confirmed \\
\hline Audience's attracting attention & 0.676 & 11.238 & Confirmed \\
\hline Building interest among the audience & 0.547 & 9.661 & Confirmed \\
\hline Arousing desire among the audience & 0.659 & 7.837 & Confirmed \\
\hline Mental health message & 0.524 & 6.038 & Confirmed \\
\hline Spiritual health message $\longrightarrow$ & 0.512 & 8.557 & Confirmed \\
\hline Building interest among the audience & 0.488 & 8.617 & Confirmed \\
\hline Arousing desire among the audience & 0.495 & 8.149 & Confirmed \\
\hline Spiritual health message $\longrightarrow$ Audience's action & 0.642 & 13.381 & Confirmed \\
\hline
\end{tabular}

\section{Discussion}

In the present study, by using structural modeling equations, it was attempted to study the effect of health-related messages on the behaviors of social networks' audience according to AIDA model and the significance of each of the relationship was then discovered. Given the findings of the present study, since social networks are considered as the main source of disseminating health information and given that they are extensively present in the individuals' lives, social networks have sustainable effects on the behaviors of their audience. All over the world, these media play a very significant role in physical, social, mental, and spiritual health as well as in the prevention of different kinds of diseases. These media are also regarded as an important factor affecting the behaviors of the audience. Health issues including physical, social, mental, and spiritual health that are shared on social media can quickly change the behaviors of the audience. The findings of the present study indicate that health-related messages that are read on Telegram can convince the readers that the advertised message can meet their needs and these messages play an important role in building interest, arousing the individuals, and attracting their attention. One can claim that emotion-based health-related messages that arouse the positive feeling of the individuals are likely to make the individual highly interested in the intended product or service. Moreover, according to the findings of the present study, these messages can arouse the individuals for having a specific product or service. The advertisers need to know how the reader thinks so that he/she will be able to advertise more efficiently. For arousing the readers toward the intended product or service, there are various stimuli. Depending on the kind of product or service and the customers, these stimuli need to be identified and programmed. Moreover, mental health messages affect the behaviors of the readers; these messages will help the individual have effective activities within the society in terms of thinking, mood, and behavior. They will also help him/her establish positive relationships with others, cope with problems and stresses of life, and manage to help others. The findings of the present study are in agreement with those of the studies conducted by Khashei and Zokaei [6], Bir [10], 
Yingjie [11] and Fish [12]. The limitation of this study was related to the data gathering from the audiences of telegram social network that was very time consuming for the researcher due to indirect discretion to the audience and the large sample size.

In line with the findings obtained, it is suggested that messages on physical, social, mental, and spiritual health, as well as their effects on the behaviors of the audiences, be taken into serious account. Given the strong effect of media on learning and the aggregation of health-related media messages, there is an increasing need to give special attention in this regard and help the individuals of a given society choose a healthbased lifestyle.

\section{Conclusion}

In sum, the findings proved the effect of healthrelated messages on the behaviors of social network audiences. This, will change the lifestyle pattern and control the chronic diseases at the community level.

\section{Acknowledgements}

The authors would like to express their gratitude to all individuals who participated in this study.

\section{Authors' contributions}

Study design: AD, NSS

Data collection and analysis: AD, NSS

Manuscript preparation and editing: AD, NSS

All authors have read and approved the final version.

\section{Conflict of Interest}

"The authors declare that they have no competing interests."

\section{Funding}

The author (s) received no financial support for the research, authorship, and/or publication of this article.

\section{Availability of data and materials}

The datasets used and/or analyzed during this study are available from the corresponding author on reasonable request.

\section{References}

1- Mohammadian M. Advertising management. Tehran: Horufiyeh press; 2017.

2- Doroodi H. The effect of advertised messages of media on the behaviors of consumers (in home appliances stores, western Tehran) according to AIDA model. Journal of Media Studies2013; 8(21): 111-8.

3-Hackley C.Advertising and promotion: communicating brands. Thousand Oaks, California, US: SAGE Publications Limited; 2005.

4- Khoshfar GhR, Mohammadi A, Mohammadzadeh F, Mohammdi R, Akbarzadeh F. Social security and social health. Journal of Social Studies in Iran2015; 9(1): 71102.

5- Jandaghi S. The effect of the layout of advertised message on convincing readers of health-related messages, (case study: advertised messages of blood pressure control in Semnan province). [thesis]. Faculty of Humanities, Semnan: Islamic Azad University 2016.

6- Khashei R, Zokaei MS. Representation method of health-based lifestyle in mass media; content analysis of health related messages on four media (Radio Salamat, TV, Salamat News website, and Slamat weekly). Communication Researches Quarterly2016; 23(1): 4565.

7- Motalebi MGh. The study of AIDA model's function on psychological and behavioral reactions of bank customers in Zanjan and offering a model. Quarterly Quantitative Studies in Management2010; 2; 132-63. [In 8- Dowlatyari E, Poorsoltani Zarandi H, Ghasemi H. The effect of advertisements on attracting male teens to Taekwondo gyms in Zanjan according to AIDA mode. Journal of Applied Researches of Sport Management 2015; 4(3): 107-122.

9- Birch R. CEOs share growth strategies for 2013. growth strategies. Credit Union Journal. [cited at 21 Jan 2013].

10- George P, Moschis Gilbert A, Churchill Jr. Consumer socialization: a theoretical and empirical anxlysis. J Mark Res1978; 15: 599-609.

11- Yingjie L. Automatic topic identification of healthrelated messages in online health community using text classification. Springer Plus2013; 2: 309-16.

12- Fish JA, Peters MDJ, Ramsey I, Sharplin G, Corsini N, Eckert M. Effectiveness of public health messaging and communication channels during smoke events: A rapid systematic review. J Environ Manage2017; 15; 193: 247-56.

13- Keyes CM. Social well-being. Soc Psychol Q1998; 61(2): 121-40.

14- Goldberg DP, Hillier VF. A scaled version of the general health questionnaire. Psychol Med1979; 9(1): 139-45.

15- Paloutzian RF, Ellison CW. Loneliness, spiritual well- 
being and the quality of life. In Peplau LA, Perlman D, eds. Loneliness: A Sourcebook of Current Theory, Research and Therapy. New York: John Wiley \& Sons; 1982. pp: 224-36. 16- Ghanavati M, Azar A, Gholamzadeh R. Route- structural modeling in management: application of Smart Pls software. Tehran: Negah Danesh publications; 2012. 17- Chin WW. Issues and opinions on structural equation modeling. MIS Quarterly1998; 22(1): 7-16.

Copyright $\odot 2016$ ASP Ins. This open-access article is published under the terms of the Creative Commons Attribution-NonCommercial 4.0 International License which permits Share (copy and redistribute the material in any medium or format) and Adapt (remix, transform, and build upon the material) under the Attribution-NonCommercial terms. 